\title{
The evolution of revolution: Is splintering inevitable?
}

\section{Atin Basuchoudhary and Laura Razzolini}

Atin Basuchoudhary is Professor of Economics, Virginia Military Institute, Lexington, VA, USA. The corresponding author, he may be reached at basuchoudharya@vmi.edu. Laura Razzolini is Professor of Economics, Department of Economics, Finance, and Legal Studies, University of Alabama, Tuscaloosa, AL, USA, and may be reached at lrazzolini@cba.ua.edu.

\section{Abstract}

We use an evolutionary model to study splintering within rebel groups. We assume that rebels possess cultural traits that encourage cooperation, defection (splintering), or a trigger behavior like Tit-For-Tat. We characterize the dynamic process by which rebels' discount rates determine whether splintering will occur in the rebel population even when cooperation is otherwise efficient. The results suggest that political action by governments that make rebels impatient also increases the likelihood of rebel group splintering. This may be counterproductive from a government's point of view. Our article closes a gap in the literature by providing a theoretical model for how rebel groups form. Policies that affect the patience of rebels and change the cultural context within rebel groups influence the likelihood of rebel group splintering. This article's contribution to the literature is twofold. First, it applies an established modeling approach to understand how even otherwise cohesive rebellions can splinter as a consequence of exogenous shocks that change rebels' time horizons. Second, we highlight how cultural context can influence this splintering process.

A nalysis of conflict often suggests that rebels do not always cooperate. Rebels often begin by cooperating but then splinter into warring factions and conflict is prolonged. The Mapping Militant Organizations, a Stanford University website, dramatically illustrates this for countries like Iraq, Pakistan, and Somalia. Other groups do not necessarily splinter, like Al-Qaeda in Iraq (AQI) for instance, which has coordinated rebellious activities in response to U.S. anti-insurgency operations. ${ }^{1}$

Using an evolutionary game-theoretic model, we analyze the process that drives splintering, or cooperation, among rebels. The rebels' goal is to produce political acts of rebellion that generate private benefits for the rebel population, even as these acts may be socially disruptive. When rebels cooperate, the number of political acts produced is controlled and restricted, thus leaving space for productive activity of a nonpolitical nature. However, if rebels splinter, competitive pressure increases the number of political acts produced at the expense of nonpolitical acts. Thus, from the perspective of productive nonpolitical activity, cooperative rebels are better for society than splintered or defecting rebels. From the rebels' perspective, likewise, cooperation is better than splintering as well, as cooperation maximizes rents. ${ }^{2}$

The question, then, is why rebels do not always cooperate with each other. To address this, we build a theoretical model that seeks to identify fundamental conditions under which rebel groups splinter (or cohere).
We use a standard evolutionary model to study the evolution of cooperation among rebels. Rebels belong to one of three cultures, a culture of cooperation, defection, or else a trigger culture (explained later on). Rebels are boundedly rational in the sense that they do not strategize about whether to cooperate or not. Instead, replicator dynamics guide their behavior, i.e., if cooperation guarantees greater benefits than defection, the proportion of rebels in the population who follow (replicate) a culture of cooperation will be larger than the proportion of rebels adhering to a culture of defection. Rather than focusing on optimal individual strategies, this modeling approach aims to elucidate what sort of behavior is more likely to be successful in a population as a whole. Moreover, this type of modeling shows how the splintering (or cooperative) process may evolve as a consequence of changing cultural or warfighting contexts. ${ }^{3}$

A policy implication of our model is that counterinsurgency interventions aimed at increasing rebels' degree of patience are more likely to promote rebel group cohesion, while interventions aimed at directly changing the proportions of different rebel cultures through attrition, coercion, or persuasion will contribute to rebel group splintering. For instance, by selectively killing all those belonging to a certain rebel culture, or by altering rebels' time horizon, a militaristic counter-rebel policy may encourage rebel splintering if it changes the distribution of cultures among rebels. Our modeling approach can be used to predict whether or not militant groups will coordinate their actions against the national government. 
Table 1: The basic evolutionary stage game

$\begin{array}{ccc} & \text { Cooperate } & \text { Defect } \\ \text { Cooperate } & e / 2 & 0 \\ & \mathrm{e} / 2 & \alpha e \\ \text { Defect } & \alpha e & \alpha(e / 2) \\ & 0 & \alpha(e / 2)\end{array}$

Note: The first row in each payoff cell is for the row player, the second row is for the column player.

\section{Literature review}

A strand of the conflict literature close to our approach has focused on the organization of rebel groups. It models entrepreneurial rebels who maximize current or future profits. But most of the literature that address civil strife, possible motivations of rebel leaders, choice of targets, and/or the effect of deterrence differs from our approach. ${ }^{4}$

A number of case studies have empirically explored possible causes for splintering. Several studies have found that competition among rebels for the "affection" of a particular ethnic group may encourage them to "outbid" each other in extremism and thereby increase the level of violence. Generational changes in leadership may fracture rebel groups, and government policies may exacerbate this process when killing top leaders. One scholar theorizes that extremism may increase as rebellions splinter, while others suggest that peace negotiations between the state and rebel groups may be responsible for increased splintering and concomitant violence. Existing divisions in society may also encourage splintering, while cohesive social bonds seem to discourage it. Rebels also may splinter out of disagreement over a strategy to be pursued or a tactic to be taken. Finally, government pressures may break up rebel groups because of commitment problems. But no single model captures the dynamic process to predict whether a group will break up or not. ${ }^{5}$

The model we present shows how rebels' incentive to cooperate evolves as a function of exogenous factors, such as the proportion of the population that happens to cooperate and the population's level of patience. The model thereby answers the question as to the dynamic conditions under which rebels coalesce into groups.

Recent experiments have studied cooperation and defection in the laboratory. The results support our theoretical finding that even extremely patient rebels may not cooperate. However, these studies do not explicitly study the evolution and the path of cooperation over time. Closest to our approach is one that suggests that in a finite setting, when an external
As compared to splintered rebel groups, cooperative rebels maximize the effect of their political acts even while increasing time for nonpolitical productive activity. Why then do rebel groups splinter at all? This article identifies fundamental conditions under which rebel groups are likely to split. The insights gained carry implications for government counterrebel strategy.

manipulator can arbitrarily reward or penalize players, cooperation may not evolve. We extend this result to the case when repetition is infinite and there are no external manipulators. ${ }^{6}$

We introduce the model, and the payoffs pertaining to rebels in each culture, in the next section. These payoffs determine how fit each culture is in relation to the others. In the section thereafter, we derive the conditions that determine whether a culture will succeed over time or not. In the penultimate section, we investigate the dynamics of how rebel cultures may evolve. In the final section, we discuss some policy implications of our model and conclude.

\section{The evolutionary game}

We use an evolutionary game-theoretic model to study rebel interaction. We assume, as is usual for evolutionary games, that individuals are endowed with a strategy that corresponds to an underlying culture, or "genotype". Rebels interact with each other in random pairwise encounters which determine player payoffs and the fitness of each particular culture. Rebels observe their own payoffs and those of other rebels in different cultures. Over time, they adopt, i.e., learn, fitter strategies.

Whenever a pair interacts, rebels solve a coordination game in which two actions are available: cooperate and defect. Cooperate corresponds to the concerted effort of civil war and coordinated revolution by rebels, and defect corresponds to individualistic attempts at terror-like warfare. If both rebels choose cooperate, each gets a "fitness reward" of $e / 2$, where $e$ is the total level of rents from cooperation. However, if one rebel cooperates while the other defects, then the cooperating rebel gets 0 while the defecting rebel gains $\alpha e$, where $\alpha$ captures the incentive to defect. Finally, if both rebels defect, both earn $\alpha(e / 2)$, as shown in Table $1 .^{7}$

The larger is $\alpha$, the greater is the incentive to defect. We restrict the value of $\alpha$ in $(0,1)$. For $\alpha$ in $(0,1 / 2)$ the game is a Stag Hunt (SH) game, while for $\alpha$ in $[1 / 2,1)$, the game is a Prisoner's Dilemma (PD) game. ${ }^{8}$

While it is possible for the rebels to use many different strategies over time, we focus on three particular strategies, or cultures. Researchers have identified, in the context of a PD game, the strategies most commonly used by players when 
Table 2: The evolutionary stage game for repeated cultural interaction

$\begin{array}{cccc} & \begin{array}{c}\text { Always } \\ \text { cooperate }\end{array} & \begin{array}{c}\text { Always } \\ \text { defect }\end{array} & \text { TFT } \\ \text { Always } & e / 2(1-\delta) & 0 & e / 2(1-\delta) \\ \text { cooperate } & e / 2(1-\delta) & \alpha \mathrm{e} /(1-\delta) & e / 2(1-\delta) \\ \text { Always } & \alpha \mathrm{e} /(1-\delta) & \alpha \mathrm{e} / 2(1-\delta) & \alpha \mathrm{e}+\delta \alpha \mathrm{e} / 2(1-\delta) \\ \text { defect } & 0 & \alpha \mathrm{e} / 2(1-\delta) & 0+\delta \alpha \mathrm{e} / 2(1-\delta) \\ \text { TFT } & e / 2(1-\delta) & 0+\delta \alpha \mathrm{e} / 2(1-\delta) & e / 2(1-\delta) \\ & e / 2(1-\delta) & \alpha \mathrm{e}+\delta \alpha \mathrm{e} / 2(1-\delta) & e / 2(1-\delta)\end{array}$

Note: The first row in each payoff cell is for the row player, the second row is for the column player.

repeatedly interacting over time. One strategy or culture is to choose to always cooperate. A second strategy is to always defect, the individualistic action. A third commonly used strategy is the Tit-For-Tat (TFT), or trigger, strategy. Here, behavior depends on what the other player has chosen to do in the prior time period. A rebel playing TFT will choose cooperate at the beginning of the pairwise interaction and then, in any subsequent period, will select the action chosen by the player with whom s/he was matched in the prior period.'

The players' payoffs from pairwise interactions over time are shown in Table 2. The payoffs for the cases in which both rebels choose always cooperate or always defect are as shown in the Table 1, but discounted by the term $(1-\delta)$ to account for infinite repetition of the interaction. The discount rate, $\delta$, measures the rebels' level of patience. A value close (but not equal) to 1 indicates high willingness to wait for later rewards. In contrast, a low level is a sign of impatience and inability to wait for future rewards.

If a rebel from a defector culture meets a cooperator, then the defector's payoff is $\alpha e /(1-\delta)$, while the cooperator's payoff is zero. When one of the two rebels is endowed with the TFT strategy, if s/he meets a cooperator, they will cooperate in the first and in every subsequent period. Both players' payoff is $e / 2(1-\delta)$, i.e., $e / 2$ as in Table 1 , but discounted. The same payoff is obtained if the TFT rebel interacts with another TFT player. In contrast, if the TFT player meets a defector then, in the first period, the TFT rebel will cooperate, while the other player will defect. In every future period, therefore, both rebels defect, wherefore the TFT rebel's payoff is $0+\delta \alpha e / 2(1-\delta)$, while the defector's is somewhat larger at $\alpha e+\delta \alpha e / 2(1-\delta)$. The second term in both expressions corresponds to the payoff from defecting forever while interacting with a defector. The first term for the TFT player is the payoff from cooperating while interacting with a defector (i.e., 0), while the first term for the defecting player is the payoff from defecting while interacting with a cooperator (i.e., $\alpha e$ ).

Table 2 captures the evolutionary stage game and we will use replicator dynamics to check the evolutionary stability of each strategy. Replicator dynamics guide players' behavior based on the notion of Darwinian selection: A strategy with higher relative payoffs will tend to grow within the population; strategies that yield lower payoffs will tend to die out. As individuals are randomly matched and play the stage game, replicator dynamics predict the evolution of play over time as a function of the relative average fitness of each strategy in the population at each point in time. The replicator dynamic process determines so-called basins of attraction, which are unstable population mixes of strategies. Within a basin, attractors are regions where the certain mix of strategies becomes stable. ${ }^{10}$

Let $p_{C}$ denote the initial proportion of cooperators in the population, and $p_{T}$ the initial proportion of TFT rebels. Consequently, since the strategy proportions must sum to 1 , the initial proportion of defectors is $1-p_{C}-p_{T}$. The expected fitness for the always cooperate, always defect, and TFT strategies are, respectively, as follows:

(1) $E \pi_{C}=p_{C}\left(\frac{e}{2(1-\delta)}\right)+p_{D} 0+p_{T}\left(\frac{e}{2(1-\delta)}\right)$,

(2) $E \pi_{D}=p_{C}\left(\frac{\alpha e}{(1-\delta)}\right)+p_{D}\left(\frac{\alpha e}{2(1-\delta)}\right)+p_{T}\left(\alpha e+\frac{\delta \alpha e}{2(1-\delta)}\right)$,

(3) $E \pi_{T F T}=p_{C}\left(\frac{e}{2(1-\delta)}\right)+p_{D}\left(\frac{\delta \alpha e}{2(1-\delta)}\right)+p_{T}\left(\frac{e}{2(1-\delta)}\right) \cdot{ }^{11}$

Given the initial distribution in the population of cooperators, defectors, and TFT-players, some strategies will be fitter than others. To compare the average fitness of the TFT strategy with that of the always cooperate strategy, consider equations (1) and (3). TFT is fitter (or greater) than always cooperate when

$$
\left(\frac{e}{2(1-\delta)}\right)\left[\left(p_{C}+p_{T}\right)(1-\delta \alpha)+\delta \alpha\right]>\left(\frac{e}{2(1-\delta)}\right)\left(p_{C}+p_{T}\right),
$$

an expression that simplifies to

(4) $p_{C}+p_{T}<1$

Inequality (4) is depicted in Figure 1. The shaded region 
shows the proportions of players such that TFT is fitter than the always cooperate strategy. The boundary is negatively sloped and independent of the patience parameter, $\delta$. Moreover, the $p_{C}$ and $p_{T}$ intercept are always at $1 .{ }^{12}$ Since the proportions of players endowed with a particular strategy never exceed 1, constraint (4) will always bind. In other words, the TFT strategy will always be fitter than the always cooperate strategy in this evolutionary setting. This leads to the following result.

Result 1. The fitness of the TFT strategy is independent of $\delta$ and, for all values of $p_{C}, p_{T} \in(0,1)$, always exceeds the fitness of the always cooperate strategy.

To compare the average fitness of TFT and always defect, consider equations (2) and (3). TFT is fitter than always defect for an expression that simplifies to

(5) $p_{C}>\frac{\alpha(1-\delta)}{[1-\alpha(1+\delta)]}-\frac{(1-\alpha) p_{T}}{[1-\alpha(1+\delta)]}$.

The slope of inequality (5), $d p_{C} / d p_{T}=(1-\alpha) /[\alpha(\delta+1)-1]$, decreases as $\delta$ rises and is positive or negative depending on whether $\alpha(1+\delta)>1$ or $<1$, respectively. When $\alpha<1 / 2$, the game is a Stag Hunt game and, for any plausible value of $\delta$, $\alpha(1+\delta)<1$. Inequality (5) will then have a negative slope. Figures $\mathrm{A} 2 \mathrm{a}$ and $\mathrm{A} 2 \mathrm{~b}$ (in the Appendix) depict the inequality for $\alpha=0.2$ and two different values of $\delta(0.27 ; 0.77)$. In the shaded regions, the TFT strategy is fitter than always defect. As $\delta$ rises, the inequality's slope falls, while remaining negative, and both the horizontal and vertical intercepts become smaller. ${ }^{13}$ Therefore, the shaded areas increase with $\delta$ as inequality (5) shifts toward the origin at which point $\delta=1$. We can then state:

Result 2. For $\alpha<1 / 2$, the space in $R^{+}$(where the population proportions that guarantee the TFT strategy to be fitter than the always defect strategy) gets larger as $\delta$ increases.

Thus, in a Stag Hunt setup (with $\alpha<1 / 2$ ) an increase in $\delta$ increases the likelihood that TFT is fitter than always defect.

When $\alpha>1 / 2$, the stage game is a Prisoners' Dilemma game and inequality (5)'s slope can be either positive or negative, depending on $\alpha(1+\delta)>1$ or $\alpha(1+\delta)<1$, respectively. Figures $\mathrm{A} 3 \mathrm{a}$ and $\mathrm{A} 3 \mathrm{~b}$ (in the Appendix) depict the inequality for $\alpha=$ 0.75 and two different values of $\delta(0.07 ; 0.75)$. Note that the inequality will pivot so that the slope becomes positive. This leads to:

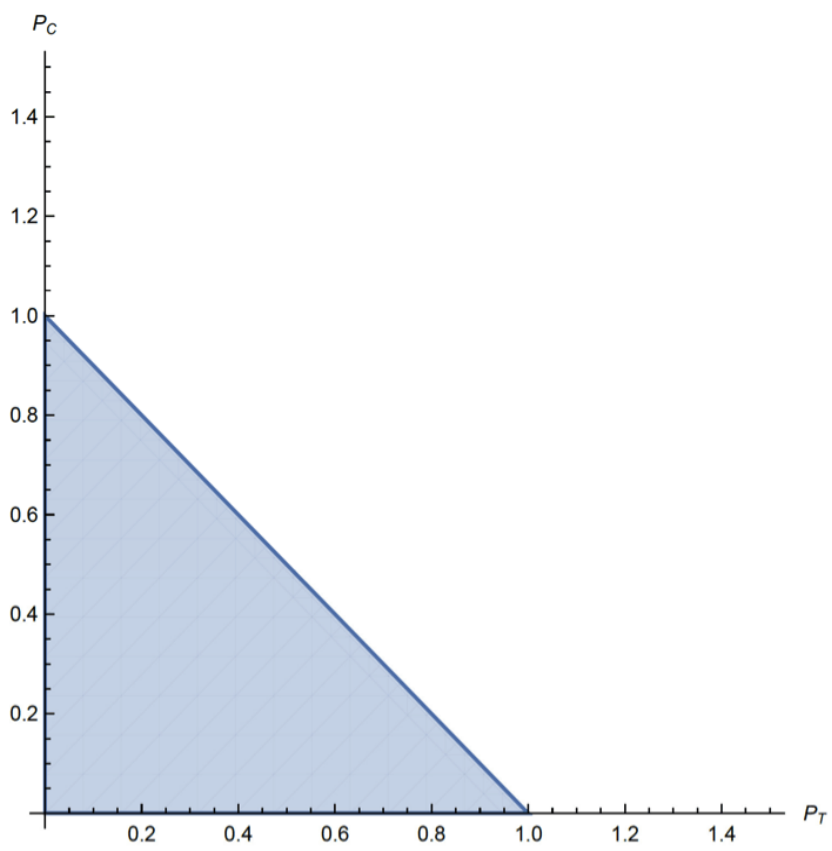

Figure 1: Inequality (4).

Result 3. For $\alpha>1 / 2$, the slope of inequality (5) switches from negative to positive as $\delta$ rises. This changes the proportions of $p_{C}$ and $p_{T}$ for which TFT is fitter than always defect.

Finally, to compare the average fitness of the always defect and always cooperate strategies, consider equations (1) and (2). Always defect is fitter than always cooperate in an expression that simplifies to

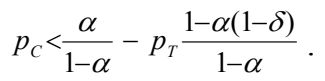

Figures A4a to A4d (in the Appendix) show inequality (6) for different values of $\alpha$ and $\delta .^{14}$ Inequality (6) is always negatively sloped. For any $\alpha$, the vertical intercept does not change with $\delta$. However, the slope in inequality (6) becomes steeper as $\delta$ rises. Again, the shaded regions indicate the proportions of players in the three cultures such that always defect is fitter than always cooperate. This leads to

Result 4. The shaded regions, where both $p_{C}$ and $p_{T}$ are positive and always defect is fitter than always cooperate, becomes smaller as $\delta$ rises.

Our results suggest that whether a strategy (or, in our case, a rebel culture) is fitter than another depends on the initial 
distribution of the three strategies in the population. Moreover, conditional on the value of $\alpha$, changes in patience ( $\delta$ ) change the proportions of $p_{C}$ and $p_{T}$ (and therefore of $p_{D}$ ) required to support any one of the three cultures. In the next section, we analyze the three constraints that determine strategy success. This permits a three-way comparison to determine the fittest strategy for different values of $\alpha$ and $\delta$. The main point will be that, irrespective of the value of the incentive to $\operatorname{defect}(\alpha)$, an increase in patience makes the success of the TFT culture more likely. Potential policy outcomes are addressed in the section thereafter.

\section{Attractors and basins of attraction}

In this section, we focus on the dynamics of behavior change for different levels of patience, $\delta$. In our model, depending on the initial distribution of the cultures among the population, one of the three strategies will evolve to be the fittest and the proportion of rebels who adopt that fittest strategy will increase, thus changing the underlying distribution of cultures in the population. This change in distribution has important repercussions for whether a rebel group will follow a path of defection and eventually splinter or not. We find that for high enough levels of patience, TFT may be an attractor. This, in turn, may lead to cohesive rebel groups. However, defection may also be an attractor, even when rebels have an extraordinarily high level of patience. In other words, the dynamics of the changes in the distribution of the strategy cultures depend on both the initial distribution of these cultures and on the patience of rebels.

We noted in the previous section that the relative fitness of the three strategies depends on $\delta$. Proposition 1 below states how the regions bounded by inequalities (4), (5), and (6) change as $\delta$ changes. Thus, Proposition 1 delineates the basins of attraction. We then simulate the effect of a change in $\delta$ for two cases, namely, $\alpha<1 / 2$ and $\alpha>1 / 2$. This is done to illustrate the effect of a varying $\delta$ on the dynamics of changes in the proportion of rebels who will follow a particular culture.

Proposition 1. Inequality (4) is the locus of the point of intersection between inequalities (5) and (6).

Proof. Let $p_{C}{ }^{*}$ and $p_{T}{ }^{*}$ be the solutions for inequalities (5) and (6). Solving, we get the following values:

$$
\left(p_{T}^{*}=\frac{2 \alpha-1}{\alpha \delta}, p_{C}^{*}=\frac{\alpha \delta-2 \alpha+1}{\alpha \delta}\right), \alpha \neq 1
$$

and $-\frac{1-\alpha}{1-\alpha+\alpha \delta}+\frac{-1+\alpha+\alpha \delta}{-1+\alpha} \neq 0$

and $1-\alpha(1-\delta) \neq 0 . .^{15}$

However, in the first of these expressions $(2 \alpha-1) /(\alpha \delta)+$ $(\alpha \delta-2 \alpha+1) /(\alpha \delta)=1$ so that adding $p_{C}{ }^{*}$ and $p_{T}{ }^{*}$ yields 1 and conforms to (4). This proves Proposition 1.

Corollary 1. The locus of the intersection of inequalities (5) and (6) tracks down inequality (4) as $\delta$ rises.

As $p_{T}{ }^{*}$ is negative for $\alpha<1 / 2$ and falls as $\delta$ rises, $p_{T}{ }^{*}$ slides down (4) as $\delta$ rises. Further, $p_{C}{ }^{*}$ is always positive for $0<\alpha$, $\delta<1$ and falls as $\delta$ rises. Thus, $p_{C}{ }^{*}$ slides down (4) to the right as $\delta$ rises as well. Put differently, $p_{C}{ }^{*}$ and $p_{T}{ }^{*}$, the locus of the intersection of (5) and (6), slide down (4) as $\delta$ rises.

Proposition 1 and Corollary 1 describe the changes in the basins of attraction as a function of $\alpha$ and $\delta$. As indicated, in what follows we consider two cases, $\alpha<1 / 2$ and $\alpha>1 / 2$. For each, we show how an increase in $\delta$ makes the evolution of a TFT culture likelier, although not certain.

Case 1: $\alpha<1 / 2$

Figures A5a and A5b represent inequalities (4), (5), and (6) for $\alpha=0.25$ and for $\delta=0.33$ and 0.75 , respectively. We identify three regions, A, B, and C. Region A is bounded by (4) and (6), $B$ by (5) and (6), and C by (5) and the origin. TFT is the fittest culture in region A. Defect is the fittest culture in regions $B$ and C. From (6), the horizontal intercept falls as $\delta$ rises while the vertical intercept remains unchanged. Inequality (4), of course, is independent of both $\alpha$ and $\delta$. This implies that region $\mathrm{A}$, where TFT is the fittest strategy, becomes larger as $\delta$ rises. Obviously, regions B and C become smaller as a result.

If the initial distribution of the population proportion of always cooperate and of TFT rebels lies in regions B or C, then the population proportion of the always defect culture will increase. Conversely, if the initial distribution of the population proportion lies in region A, then the TFT culture will prevail and the population proportion of the TFT culture will increase. ${ }^{16}$ As $\delta$ rises, region A, the only region where TFT is fitter, will expand. ${ }^{17}$ That is, as the patience parameter $\delta$ rises, the likelihood of cooperation, through TFT, increases. For example, say the initial distribution of cultures lies in region B. This implies that rebels are incentivized to choose the defect culture, with the result that the rebel group splinters. Now say patience, $\delta$, rises from 0.33 to 0.75 . The same distribution may now lie in region A because of the shift in inequality (6). Here, rebels are 
incentivized to cooperate through the TFT culture. Thus, an increase in patience makes splintering less likely. Of course, the converse is also true. Nevertheless, and whatever the level of patience, if rebel culture distributions lie in regions B and $\mathrm{C}$, splintering is inevitable.

Case 2: $\alpha>1 / 2$

Figures A6a and A6b represent inequalities (4), (5), and (6) for $\alpha=0.6$ and for $\delta=0.33$ and 0.75 , respectively. Once more, we identify three regions, in this case D, E, and F. The always defect strategy is fittest in region D. TFT is the fittest strategy in regions $\mathrm{E}$ and $\mathrm{F} .{ }^{18}$ These regions are illustrated in Figure $\mathrm{A} 6 \mathrm{~b}$. where $\delta$ is 0.75 . However, regions $\mathrm{E}$ and $\mathrm{F}$ are null sets when $\delta$ is 0.33 in Figure A6a since (5) and (6) no longer are binding constraints. ${ }^{19}$ This increases the likelihood that cooperation, through TFT, will emerge in a society where $\delta$ is higher. For example, say the population distribution of rebel cultures lies in region $\mathrm{E}$ when $\delta$ is 0.75 . Now if for some reason $\delta$ falls from 0.75 to 0.33 , the same distribution of cultures will incentivize the defect culture and the rebels within the group will defect, thus splintering the rebel group. Thus, as in the previous case, a decrease in patience makes splintering more likely. Again, the converse is also true. Nevertheless, whatever the level of patience, splintering is inevitable if rebel culture distributions are in region $\mathrm{D}$.

\section{Discussion and conclusions}

Our model suggests that both, the level of patience and the initial distribution of the population among the different cultures matter in determining the evolution of play.

Defection becomes more likely as patience, $\delta$, decreases. That is, rebel groups are more likely to splinter if rebels become less patient and therefore more likely to defect. For example, say an exogenous shock (like an assault on rebel groups by the state) reduces rebels' time horizon for decisionmaking and thus lowers their discount rate. According to our model, rebel group splintering is expected to increase. This is a testable hypothesis.

We also note that the initial distribution of cultures among the rebel population matters. Thus, if this distribution lies in regions B, C, or D (across the Figure A5 and Figure A6 sets) rebels will defect, i.e., the rebel group will splinter regardless of whatever is the level of patience. In these scenarios, rebel group cohesion becomes impossible. As the consequences are observable, our model generates further testable hypotheses. For example, military actions that change the distribution of cultures in a population may explain the success of policies such as the Anbar Awakening, a policy adopted by the United States in Iraq in 2007. This policy strengthened local Iraqi
Sunni's at the expense of foreign fighters. At that time, Iraqi Sunni forces coalesced against the violent depredations of Al Qaeda in Iraq (AQI). It is possible to argue that local Sunni's were more likely to cooperate with each other through a TFT mechanism because they lived in the country and had families, history, and a future in Iraq. The foreign AQI members had no long-term stake in Iraq and, as a consequence, were more likely to have a defect culture. As the U.S. policy continued, Iraqi Sunni's became relatively more numerous and this could have contributed to the change in behavior that led to the Anbar Awakening.

Whether rebels will splinter or not may thus be rooted in prevailing cultural norms. A purely militaristic approach, even if it is successful in separating TFT from defector rebels, as in the Anbar Awakening, therefore may not be sufficient to prevent the splintering of rebel movements into more violent offshoots. Political institutions that provide peaceful political change and economic institutions that reduce the need for appropriative political acts prevent splintering and violence and increase the bargaining space for negotiated settlements. Further, selective policing and targeting of rebel cultures might change the distribution of cultures itself. For example, if the initial distribution of rebels lies in region B or C of Figure A5a, we can expect splintering. Even if the initial distribution lies in region $\mathrm{A}$, cooperation enforced through a trigger strategy is still possible. If the state selectively targets established groups who have the means to enforce cohesion through a TFT strategy, this might reduce the proportion of rebels belonging to this culture relative to the defect culture. Conversely, state action may also reduce the proportion of rebels adhering to the TFT strategy and therefore splinter a cohesive rebellion. Such splintering would increase policing costs for the state and may lead to state failure as rebel violence among different groups and with the state spreads and the prospects of a negotiated peace diminishes as it becomes harder to bargain with a hydra-like rebellion. In contrast, this sort of division may make it easier for the state to weaken the rebellion, more so if the rebellion can be localized. These lines of thinking suggest that modeling the state as a strategic agent interacting with different rebel cultures should be the next step in our theoretical model. ${ }^{20}$

This article closes a gap in the conflict literature by developing a model that captures evolutionary pathways for rebel group cohesion. The model provides testable hypotheses and carries policy implications subject to the existence of evidence for these hypotheses. We argue that rebels' patience as well as the initial proportion of rebels who adhere to a culture of cooperative behavior relative to others drive rebel group cohesion. Thus, violent suppression of rebellions, insofar as it reduces the patience of rebels, is likely to lead to the splintering 
of rebel groups, more competition among them, and therefore to more violence. Conversely, targeting specific cultural traits, such as enhancing the ability of rebels to punish defectors by separating different types of rebels, may help build rebel cohesion. This may be more effective than violence at stamping out rebellions as it may be easier to negotiate with a cohesive group of rebels. That cohesive rebellions also leave more productive economic space further suggests that state failure due to economic collapse is less likely when rebel cultures are targeted. This, too, increases the chance of a negotiated peace by making prospects for economic prosperity a viable alternative.

\section{Notes}

1. Mapping website: See Crenshaw (2012). Other groups: Cigar (2011).

2. Produce political acts of rebellion: (U.S. Dept. of the Army, 2007, pp. 1-19). Leaving space for nonpolitical acts: Tullock (1974), Collier and Hoeffler (1998; 2002). Competitive pressure: Bloom (2005), Cunningham (2011), Cunningham, et al. (2012), Lilja (2012), Pearlman (2008/2009).

3. Standard evolutionary model: See, e.g., McElreath and Boyd (2007), Harrington (2009, pp. 521-529).

4. A strand: See, e.g., Grossman (1991), Collier, et al. (2003), Anderton and Carter (2009). Differs from: See, among others, Gurr (1968), Tellis, Szayna, and Winnefield (1997), Hegre, et al. (2001), Mousseau (2001), Fearon and Laitin (2003), Collier and Hoeffler (2004), Frey (2004), Herbst (2004), Basuchoudhary and Shughart (2010), Goldstone, et al. (2010).

5. Outbid: Bloom (2005), Pearlman (2008/2009), Cunningham (2011), Cunningham, Bakke, and Seymour (2012), Lilja (2012). Generational changes: Lawrence (2010). Government policies: Girardet (2011). One scholar: Bueno de Mesquita (2008). Other scholars: Kydd and Walter (2002). Existing divisions: See Christia (2008), Kalyvas (2006). Cohesive social bonds: Staniland (2012). Disagreement over strategy or tactic: Zirakzadeh (2002), Moghadam and Fishman (2010). Commitment problems: Bapat and Bond (2012).

6. Recent experimental studies: Duffy and Ochs (2009), Dal Bo and Frechette (2011). Closest to our approach: Vasin (2006).

7. The model is based on Basuchoudhary, Siemers, and Allen (2010).

8. For any value of $\alpha$, the gains from cooperation exceed the payoff from any other combination of strategies. This payoff structure implicitly accommodates coordination costs (see Anderton and Carter, 2009, pp. 142-146).

9. Researchers have identified: Dal Bo and Frechette (2011). Another oft-used strategy is called Grim. This is equivalent to the TFT strategy when played against always cooperate or always defect: A rebel will choose to cooperate so long as the other player also cooperates. If the other player defects, however, then the rebel will defect forevermore.

10. For a textbook treatment, see Harrington (2009, pp. 521-529).

11. Equation (3) refers to the payoff from TFT, hence the subscript. To maintain a distinction, we use the subscript $T$ for the proportion of TFT players and TFT for the payoff.

12. This is a binding constraint. The inequalities may have actual, but nonbinding, intercepts that exceed 1 .

13. The horizontal intercept in Figures $2 \mathrm{a}$ and $2 \mathrm{~b}$ becomes smaller as $\delta$ rises. Considering the vertical intercept in the figures, both the numerator and the denominator fall at the same rate $\alpha$, as $\delta$ rises. However, the vertical intercept is greater or less than 1 only if $\alpha(1-\delta)<$ or $>1-\alpha(1+\delta)$, respectively. Trivially, the vertical intercept is always less than one for $\alpha$ less than $1 / 2$. Thus, (i) if both the numerator and the denominator fall at the same rate which is independent of $\delta$ and (ii) the denominator is always larger than the numerator when $\alpha<1 / 2$, then the vertical intercept term falls as $\delta$ rises.

14. Figures $4 \mathrm{a}$ and $4 \mathrm{~b}$ show the effect of a change in $\delta(\delta$ rises from 0.36 to 0.75 ) when $\alpha<1 / 2$ (in particular, $\alpha=0.33$ ), i.e., Stag Hunt. Figures $4 \mathrm{c}$ and $4 \mathrm{~d}$ show the effect of the same change in $\delta$ when $\alpha>1 / 2$ (in particular, $\alpha=0.7$ ), i.e., Prisoners' Dilemma.

15. Note that the conditions for getting an internal solution do not violate our assumptions that $\alpha, \delta \in(0,1)$.

16. Figures 1 through 4 in the prior section define these areas.

17. Proposition 1 and Corollary 1 ensure this.

18. Figures 1 through 4 in the prior section define these areas.

19. Proposition 1 and Corollary 1 ensure that regions $\mathrm{E}$ and $\mathrm{F}$ become smaller and ultimately disappear as $\delta$ rises when $\alpha>1 / 2$. 20. Increase the bargaining space: See Hirshleifer (1995).

\section{References}

Anderton, C.H. and J.R. Carter. 2009. Principles of Conflict Economics. New York: Cambridge University Press. https://doi.org/10.1017/CBO9780511813474

Basuchoudhary, A. and W.F. Shughart II. 2010. "On Ethnic Conflict and the Origins of Transnational Terrorism." Defense and Peace Economics. Vol. 21, No. 1, pp. 65-87. https://doi.org/10.1080/10242690902868343

Basuchoudhary, A., T. Siemers, and S.K. Allen. 2010. "Civilization and the Evolution of Short Sighted Agents." Virginia Economic Journal. Vol. 15, pp. 11-33.

Bapat, N.A. and K.D. Bond. 2012. "Alliances Between Militant Groups." British Journal of Political Science. Vol. 42, No. 4, pp. 1-32. https://doi.org/10.1017/S000712341100007X

Bloom, M.M. 2005. Dying to Kill: The Allure of Suicide Terror. New York: Columbia University Press.

Bueno de Mesquita, E. 2008. "Terrorist Factions." Quarterly Journal of Political Science. Vol. 3, No. 4, pp. 399-418. https://doi.org/10.1561/100.00008006 
Christia, F. 2008. "Following the Money: Muslim versus Muslim in Bosnia's Civil War." Comparative Politics. Vol. 40, No. 4, pp. 461-480. https://doi.org/10.5129/001041508X12911362383390

Cigar, N. 2011. "Al Qaeda, the Tribes, and the Government." MES Occasional Paper Series 2. Quantico, VA: Marine Corps University.

Collier, P. and A. Hoeffler. 1998. "On Economic Causes of Civil War." Oxford Economic Papers. Vol. 50, No. 4, pp. 563-573.

https://doi.org/10.1093/oep/50.4.563

Collier, P. and A. Hoeffler. 2002. "On the Incidence of Civil War in Africa." Journal of Conflict Resolution. Vol. 46, No. 1, pp. 13-28. https://doi.org/10.1177/0022002702046001002

Collier, P. and A. Hoeffler. 2004. "Greed and Grievance in Civil Wars." Oxford Economic Papers. New Series. Vol. 56, No. 4, pp. 563-595. https://doi.org/10.1093/oep/gpf064

Collier, P., L. Elliot, H. Hegre, A. Hoeffler, M. Reynal-Querol, and N. Sambanis. 2003. Breaking the Conflict Trap: Civil War and Development Policy. Washington, D.C.: The World Bank.

Crenshaw, M. 2012. Mapping Militant Organizations. http://www.stanford.edu/group/mappingmilitants/cgi-bin/. FSI Stanford, CISAC, Stanford [accessed 11/10/2012].

Cunningham, K.G. 2011. "Divide and Conquer or Divide and Concede: How Do States Respond to Internally Divided Separatists?" American Political Science Review. Vol. 105, No. 2, pp. 275-297. https://doi.org/10.1017/S0003055411000013

Cunningham, K.G., K. Bakke, and L. Seymour. 2012. "Shirts Today, Skins Tomorrow: Dual Contests and the Effects of Fragmentation in Self-Determination Disputes." Journal of Conflict Resolution. Vol. 56, No. 1, pp. 67-93. https://doi.org/10.1177/0022002711429697

Dal Bo, P. and G.R. Frechette. 2011. "The Evolution of Cooperation in Infinitely Repeated Games: Experimental Evidence." American Economic Review. Vol. 101, No. 1, pp. 411-429.

https://doi.org/10.1257/aer.101.1.411

Duffy, J. and J. Ochs. 2009. "Cooperative Behavior and the Frequency of Social Interaction." Games and Economic Behavior. Vol. 66, No. 2, pp. 785-812. https://doi.org/10.1016/j.geb.2008.07.003

Fearon, J. and D. Laitin. 2003. "Ethnicity, Insurgency, and Civil War." American Political Science Review. Vol. 97, No. 1, pp. 75-90. https://doi.org/10.1017/S0003055403000534

Frey, B. 2004. Dealing with Terrorism: Stick or Carrot? Cheltenham, UK: Elgar. https://doi.org/10.4337/9781845421465

Girardet, E. 2011. “Assassin Nation: After More than Three Decades of Targeted Killings, is there Anyone Left Alive who can Actually run Afghanistan?" Foreign Policy (18 July 2011).
Goldstone, J., R. Bates, D. Epstein, T. Gurr, M. Lustick, M. Marshall, J. Ulfelder, and M. Woodward. 2010. "A Global Model for Forecasting Political Instability." American Journal of Political Science. Vol. 54, No. 1, pp. 190-208. https://doi.org/10.1111/j.1540-5907.2009.00426.x

Grossman, H.I. 1991. "A General Equilibrium Model of Insurrections." American Economic Review. Vol. 81, No. 4, pp. 912-921.

Gurr, T.R. 1968. “A Causal Model of Civil Strife: Comparative Analyses Using New Indices.” American Political Science Review. Vol. 62, No. 4, pp. 1104-1124. https://doi.org/10.2307/1953907

Harrington, J.E. 2009. Games, Strategies, and Decision Making. New York: Worth Publishers.

Hirshleifer, J. 1995. "Theorizing About Conflict," pp. 165-189 in T. Sandler and K. Hartley, eds. Handbook of Defense Economics. Vol. 1. Amsterdam: Elsevier. https://doi.org/10.1016/S1574-0013(05)80009-2

Hegre, H., T. Ellingsen, S. Gates, and N.P. Gledistch. 2001. "Toward a Democratic Civil Peace? Democracy, Political Change, and Civil War, 1816-1992." American Political Science Review. Vol. 95, No. 1, pp. 33-48.

Herbst, J. 2004. “African Militaries and Rebellion: The Political Economy of Threat and Combat Effectiveness." Journal of Peace Research. Vol. 41, No. 3, pp. 357-369. https://doi.org/10.1177/0022343304043774

Kalyvas, S.N. 2006. The Logic of Violence in Civil War. Cambridge, UK: Cambridge University Press. https://doi.org/10.1017/CBO9780511818462

Kydd, A. and B.F. Walter. 2002. "Sabotaging the Peace: The Politics of Extremist Violence." International Organization. Vol. 56, No. 2, pp. 263-296. https://doi.org/10.1162/002081802320005487

Lilja, J. 2012. "Outbidding and the Decision to Negotiate," pp. 126-153 in I.W. Zartman, M. Anstey, and P. Meerts, eds. The Slippery Slope to Genocide: Reducing Identity Conflicts and Preventing Mass Murder. Oxford, UK: Oxford University Press. https://doi.org/10.1093/acprof:oso/9780199791743.003.0007

Lawrence, A.S. 2010. "Triggering Nationalist Violence: Competition and Conflict in Uprisings against Colonial Rule." International Security. Vol. 35, No. 2, pp. 88-122. https://doi.org/10.1162/ISEC_a_00019

McElreath, R. and R. Boyd. 2007. Mathematical Models of Social Evolution: A Guide For the Perplexed. Chicago, IL: The University of Chicago Press. https://doi.org/10.7208/chicago/9780226558288.001.0001

Moghadam, A. and B. Fishman, eds. 2010. Self-Inflicted Wounds: Debates and Division Within Al Qaida and Its Periphery. Combating Terrorism Center at West Point Harmony Project (www.ctc.usma.edu).

Mousseau, D.Y. 2001. "Democratizing With Ethnic Divisions: A Source of Conflict?" Journal of Peace Research. Vol. 38, No. 5, pp. 547-567. https://doi.org/10.1177/0022343301038005001

Pearlman, W. 2008/2009. "Spoiling Inside and Out: Internal 
Political Contestation and the Middle East Peace Process." International Security. Vol. 33, No. 3, pp. 79-101.

https://doi.org/10.1162/isec.2009.33.3.79

Staniland, P. 2012. "Organizing Insurgency: Networks, Resources, and Rebellion in South Asia." International Security. Vol. 37, No. 1, pp. 142-177. https://doi.org/10.1162/ISEC_a_00091

Tellis, A.J., T.A. Szayna, and J.E. Winnefield. 1997. Anticipating Ethnic Conflict. Santa Monica, CA: RAND.

Tullock, G. 1974. "The Social Dilemma: The Economics of War and Revolution." Fairfax, VA: Center for the Study of Public Choice.

U.S. Army and Marine Corps. 2007. The U.S. Army/Marine Corps Counterinsurgency Field Manual. Foreword by David H. Petraeus, James F. Amos, and John A. Nagl. Introduction by Sarah Sewall. Chicago, IL: The University of Chicago Press.

Vasin. 2006. "The Folk Theorems in the Framework of Evolution and Cooperation," pp. 197-207 in A. Haurie, S. Muto, L.A. Petrosjan, and T.E.S. Raghavan, eds. Advances in Dynamic Games. Annals of the International Society of Dynamic Games. Vol. 8. Boston: Birkhäuser.

Zirakzadeh, C.E. 2002. "From Revolutionary Dreams to Organizational Fragmentation: Disputes over Violence within ETA and Sendero Luminoso." Terrorism and Political Violence. Vol. 14, No. 4, pp. 66-92.

https://doi.org/10.1080/714005641 


\section{Appendix: Figures A2, A3, A4, A5, and A6}

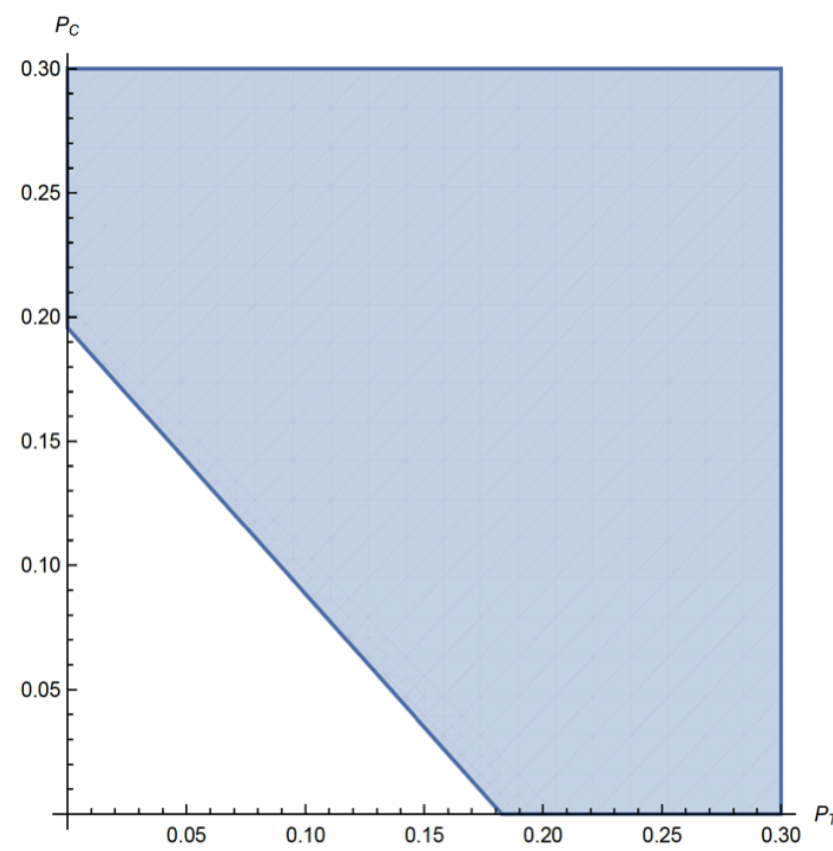

Figure A2, Panel (a): Inequality $5, \alpha=0.2, \delta=0.27$.

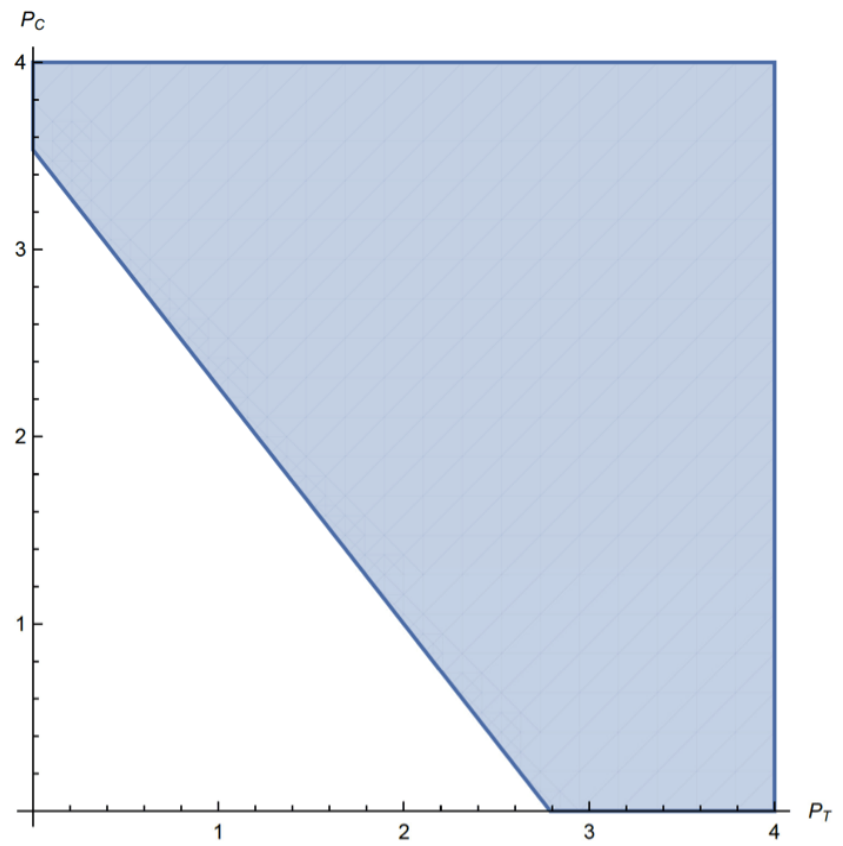

Figure A3, Panel (a): Inequality $5, \alpha=0.75, \delta=0.07$.

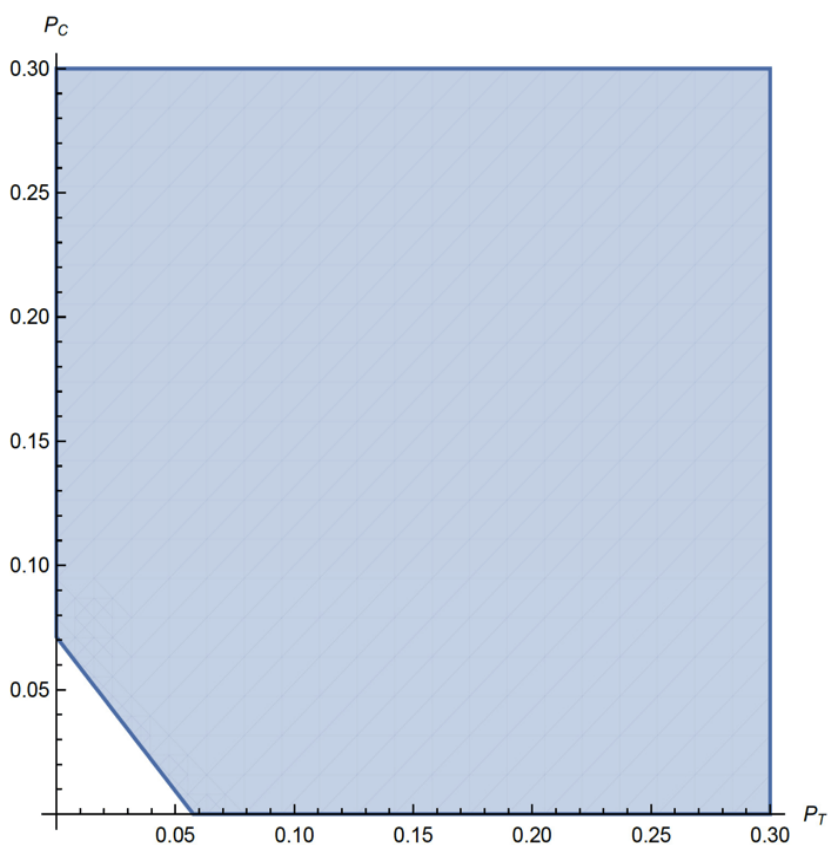

Figure A2, Panel (b): Inequality $5, \alpha=0.2, \delta=0.77$.

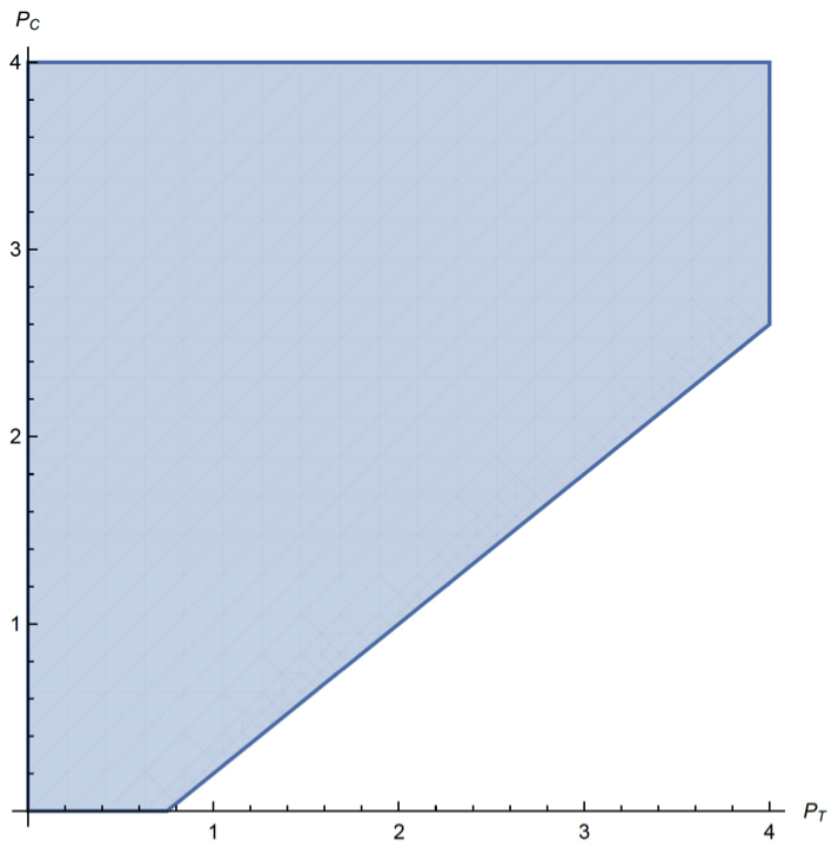

Figure A3, Panel (b): Inequality 5, $\alpha=0.75, \delta=0.75$. 


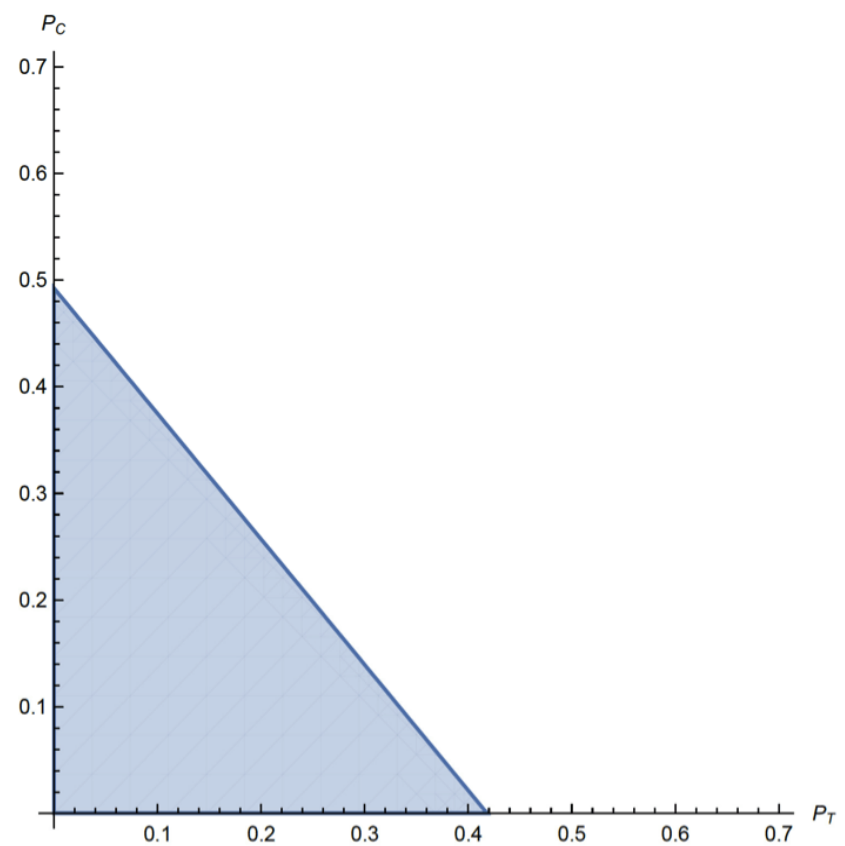

Figure A4, Panel (a): Inequality $6, \alpha=0.33$ and $\delta=0.36$.

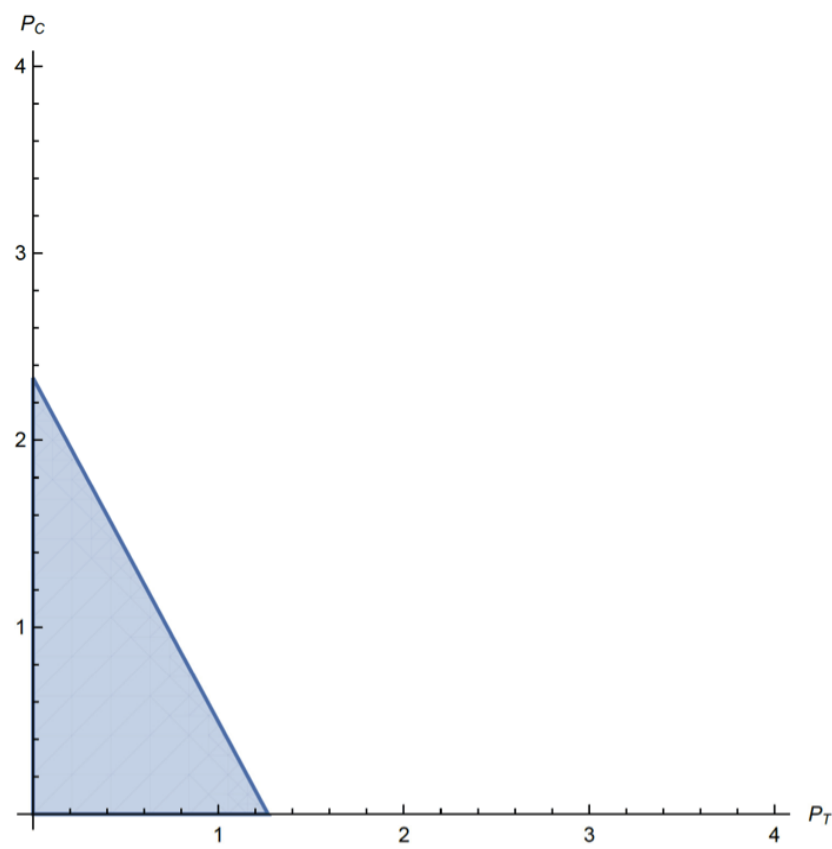

Figure A4, Panel (c): Inequality $6, \alpha=0.7$ and $\delta=0.36$.

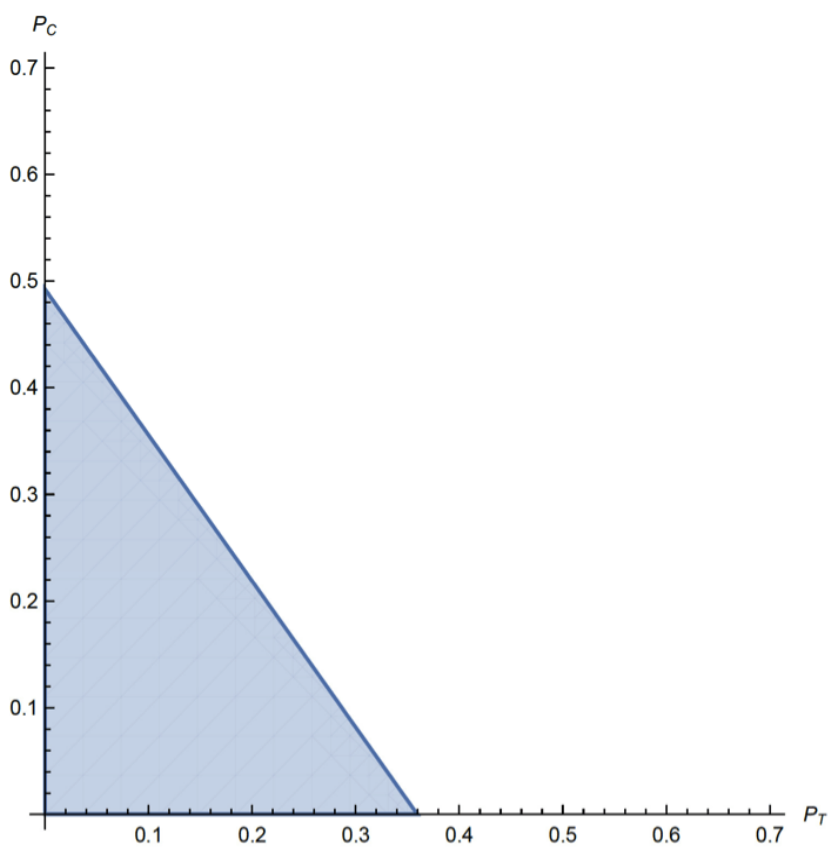

Figure A4, Panel (b): Inequality 6, $\alpha=0.33$ and $\delta=0.75$.

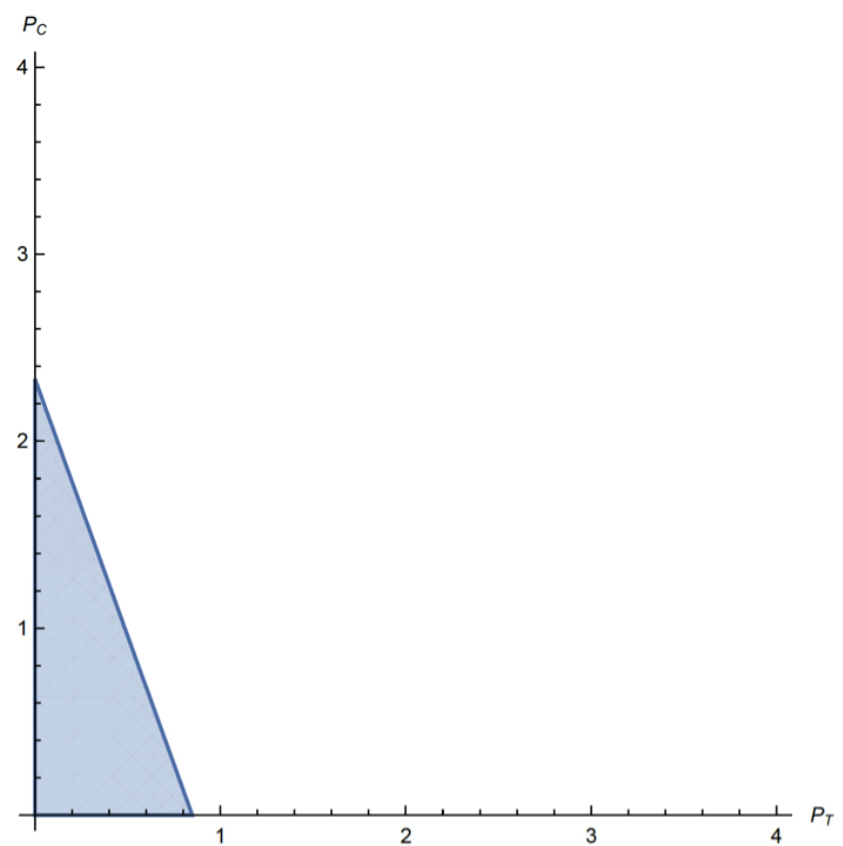

Figure A4, Panel (d): Inequality $6, \alpha=0.7$ and $\delta=0.75$. 


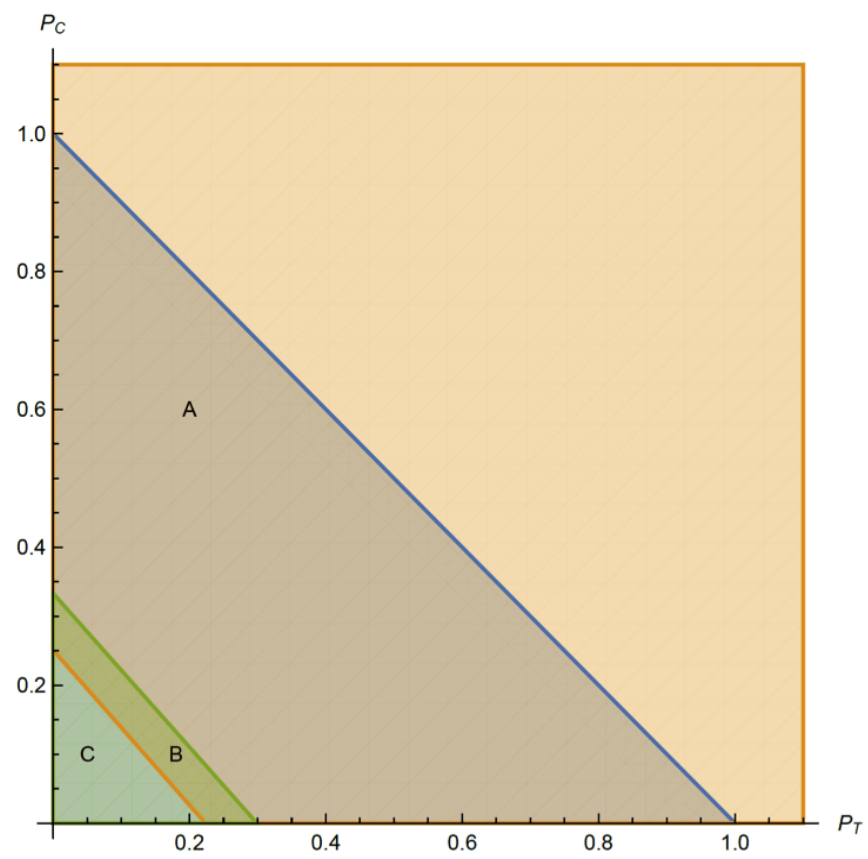

Figure A5, Panel (a): Inequalities 4, 5, and 6 with $\alpha=0.25$ and $\delta=0.33$.

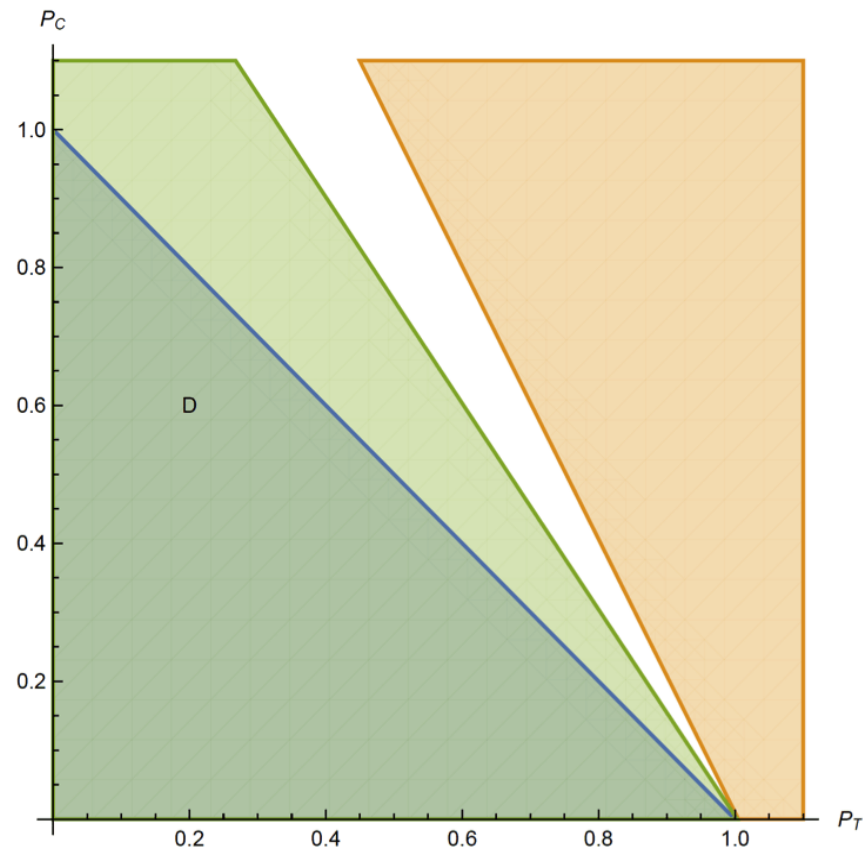

Figure A6, Panel (c): Inequalities 4, 5, and 6 with $\alpha=0.6$ and $\delta=0.33$.

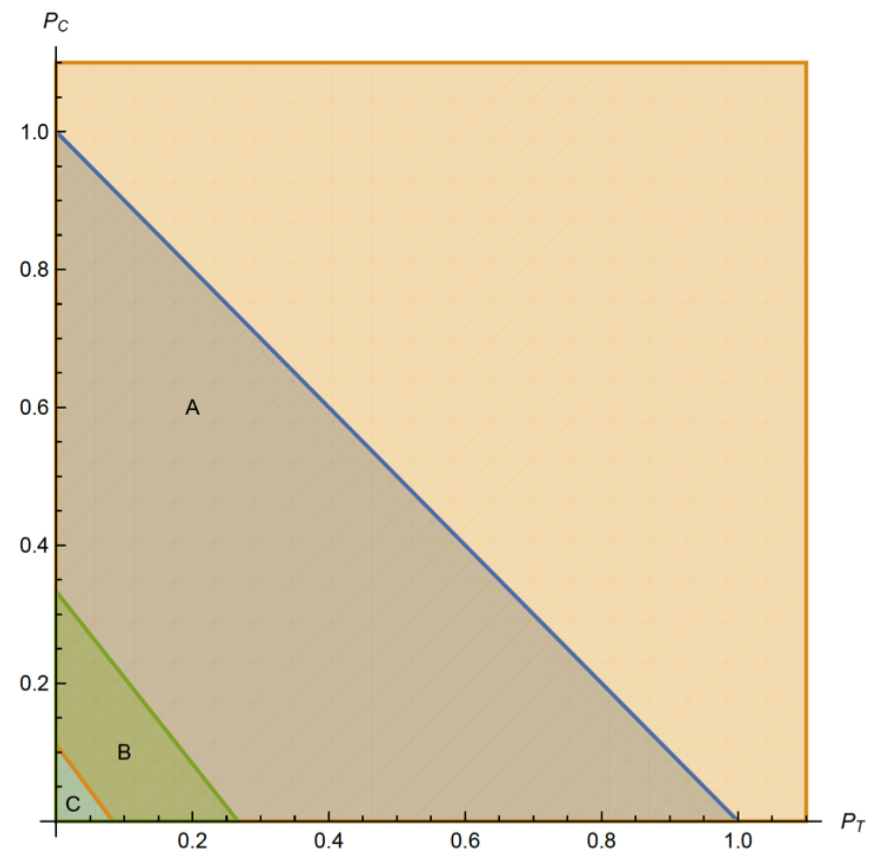

Figure A5, Panel (b): Inequalities 4, 5, and 6 with $\alpha=0.25$ and $\delta=0.75$.

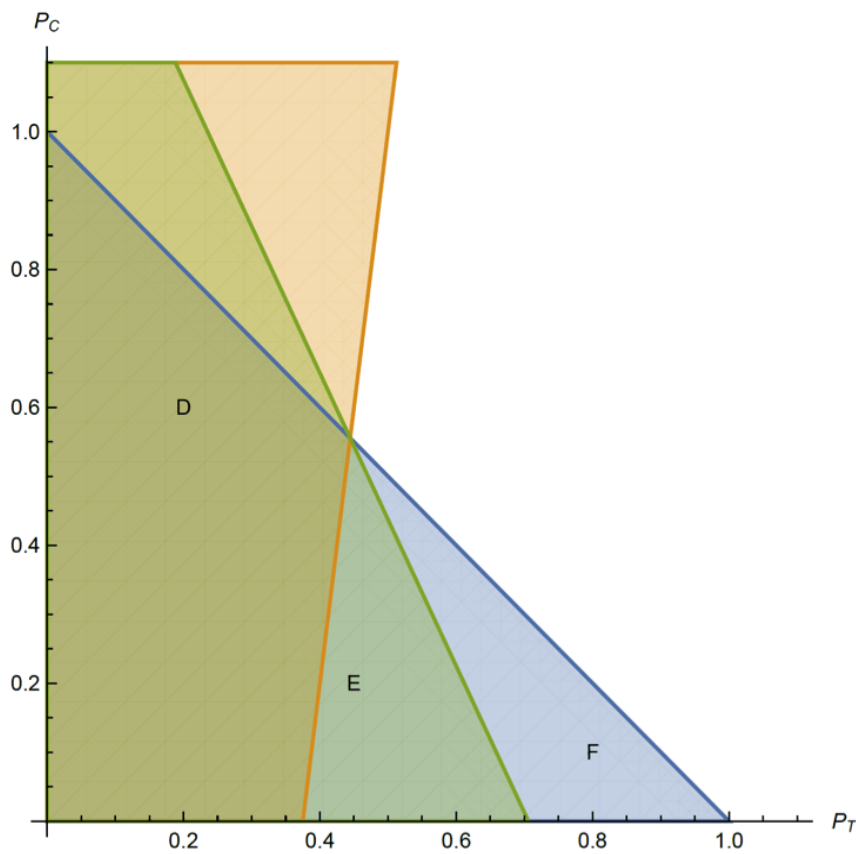

Figure A6, Panel (d): Inequalities 4, 5, and 6 with $\alpha=0.6$ and $\delta=0.75$. 